\title{
Glass transition in hyperquenched water?
}

\author{
Arising from: Y.-Z. Yue \& C. A. Angell Nature 427, 717-720 (2004)
}

It has been unclear whether amorphous glassy water heated to around $140-150 \mathrm{~K}$ remains glassy until it crystallizes or whether instead it turns into a supercooled and very viscous liquid. Yue and Angell ${ }^{1}$ compare the behaviour of glassy water under these conditions to that of hyperquenched inorganic glasses, and claim that water stays glassy as it heats up to its crystallization point; they also find a 'hidden' glassto-liquid transition at about $169 \mathrm{~K}$. Here we use differential scanning calorimetry (DSC) heating to show that hyperquenched water deposited at $140 \mathrm{~K}$ behaves as an ultraviscous liquid, the limiting structure of which depends on the cooling rate - as predicted by theoretical analysis of the liquid-to-glass transition ${ }^{2}$. Our findings are consistent with a glass-toliquid transition-onset temperature $\left(T_{\mathrm{g}}\right)$ in the

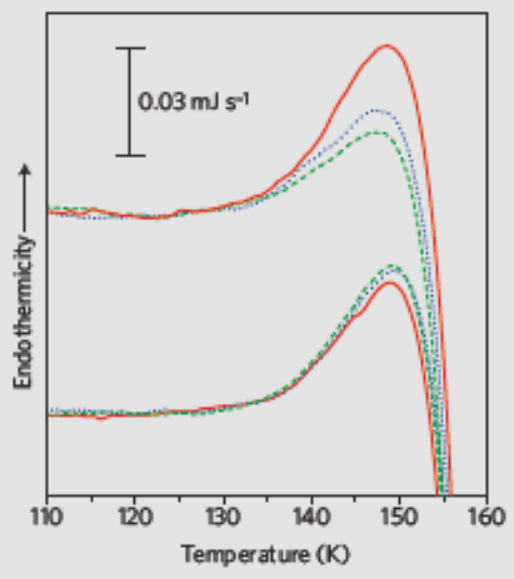

Figure 1 | Liquid-like relaxation in hyperquenched waterat or below $140 \mathrm{~K}$. Top curves: effect of cooling rate of unannealed hyperquenched water samples, after deposition at $140 \mathrm{~K}$ for $16 \mathrm{~min}$, on differential-scanning calorimetry (DSC) measurements recorded on subsequent heating at $30 \mathrm{~K} \mathrm{~min}^{-1}$; the cooling rate was increased from $0.2 \mathrm{Kmin}^{-1}$ to $2.0 \mathrm{Kmin}^{-1}$ and to $5.0 \mathrm{~K}$ $\mathrm{min}^{-1}$, and the corresponding scans are indicated by solid, dotted and dashed lines, respectively. Note the decrease in the height of the endothermic step with increasing cooling rate. Bottom curves: effect of annealing at $130 \mathrm{~K}$ for $90 \mathrm{~min}$ on hyperquenched water samples, after deposition at $140 \mathrm{~K}$ for $16 \mathrm{~min}$ and cooling at $0.2,2.0$ and $5.0 \mathrm{~K} \mathrm{~min}^{-1}$, on DSC scans recorded on subsequent heating at $30 \mathrm{~K} \mathrm{~min}^{-1}$ (line designations as in top curves). Note the disappearance of the effect of cooling rate for unannealed samples. Scans are normalized with respect to the weights and ice impurity of the samples and are drawn on the same scale. The $\Delta C_{p}$ values are corrected for $22 \%$ ice impurity ${ }^{5}$. The ordinate scale is for $1 \mathrm{mg}$ sample weight. The scans are superimposed at low temperatures. region of $136 \mathrm{~K}$ (refs 3,4), and they indicate that measurements of the liquid's properties may clarify the anomalous properties of supercooled water.

We hyperquenched micrometre-sized water droplets on a substrate held at $140 \mathrm{~K}$ (ref. 5) and immediately cooled it to $77 \mathrm{~K}$ at rates of $0.2,2.0$ and $5.0 \mathrm{~K} \mathrm{~min}^{-1}$. DSC scans recorded subsequently (Fig. 1) show that the height of the endothermic peak $\left(\Delta C_{p}\right)$ decreases with increasing cooling rate. This effect disappears in DSC scans of samples that were prepared and cooled in the same manner but which were also annealed at $130 \mathrm{~K}$ (Fig. 1).

The mean $\Delta C_{p}\left(T_{g}\right)$ values of unannealed samples after cooling are: at $0.2 \mathrm{~K} \mathrm{~min}^{-1}$, $1.7 \pm 0.3 \mathrm{~J} \mathrm{~K}^{-1} \mathrm{~mol}^{-1}(135 \pm 1 \mathrm{~K}$ ) (from 18 samples); at $2.0 \mathrm{~K} \mathrm{~min}^{-1}, 1.1 \pm 0.2 \mathrm{JK}^{-1} \mathrm{~mol}^{-1}$ $(136 \pm 2 \mathrm{~K}$ ) (from 9 samples); and at $5.0 \mathrm{~K}$ $\min ^{-1}, 0.7 \pm 0.1 \mathrm{~J} \mathrm{~K}^{-1} \mathrm{~mol}^{-1}(135 \pm 1 \mathrm{~K})$ (from 9 samples). For $T_{\mathrm{g}} \approx 136 \mathrm{~K}$, water relaxes during deposition at $140 \mathrm{~K}$ for $16 \mathrm{~min}$, moving towards metastable equilibrium.

The limiting structure obtained on subsequent cooling may be characterized in terms of a limiting 'fictive' temperature $\left(T_{\mathrm{f}}^{\prime}\right)$, which decreases with decreasing cooling rate $^{2}$. Decreasing $T_{\mathrm{f}}^{\prime}$ is experimentally observable by DSC on subsequent reheating, and is evident mainly as an increasingly pronounced overshoot ${ }^{2}$ (Fig. 1); an overshoot can also develop upon annealing below $T_{8}$ (ref. 6).

The $\Delta C_{p}$ increase of annealed samples ${ }^{4}$ (Fig. 1) contains an overshoot contribution, and water's 'true' $\Delta C_{p}$ increase at $T_{\mathrm{g}}$ must be lower, approaching the value of about $0.7 \mathrm{~J} \mathrm{~K}^{-1}$ $\mathrm{mol}^{-1}$ obtained on cooling at $5.0 \mathrm{~K} \mathrm{~min}^{-1}$. A lower $\Delta C_{p}$ value seems consistent with increasingly 'strong' behaviour of supercooled water ${ }^{7-10}$.Our findings therefore support the postulated fragile-to-strong transition of liquid water on cooling from ambient temperature into the supercooled and glassy state $e^{8,10}$.

Our results are not consistent with the sub$T_{8}$ or "shadow" peak postulated by Yue and Angell, because their criterion is that the onset temperature of the peak is the same as the annealing temperature (see Fig. $3 \mathrm{~b}$ in ref. 1). This is not observed here because $T_{\mathrm{g}}$ does not vary with annealing temperature (Fig. 1).

Ingrid Kohl*, Luis Bachmannt, Erwin Mayer*, Andreas Hallbrucker ${ }^{*}$, Thomas Loerting ${ }^{*} \dagger$ *Institute of General, Inorganic and Theoretical Chemistry, and †Institute of Physical Chemistry, University of Innsbruck, 6020 Innsbruck, Austria e-mait: ingrid.kohl@uibk.ac.at

1. Yue, Y.-Z \& Angell, C.A.Nature 427, 717-720 (2004).

2. Moynihan, C.T, Easteal, A.L. DeBolt, M.A.\& Tucker, L. L.Am. Ceram. Sac. 59,12-16 (1976)

3. Johari, G.P. Hallbruckec, A.\& Mayer, E. Nature 330, 552-553(1987)

4. Hallbruckec, A, Mayec, E.\& Johari, G. P. Phil. Mag B 60, $179-187$ (1989).

5. Kohl, L, Mayer, E\& Hallbrucker, A.Phys Chem. Chem. Phys. 2, 1579-1586 (2000)

6. Hodge, L M. \&Berens, A. R. Maramolearles 15, 762-770 (1982).

7. Angell, C. A.J. Nan-Cyst. Salids 102, 205-221 (1988),

8. Ito, K, Moynihan, C. T.\&Angell, C.A. Nature 398,492-495 (1999).

9. Debenedetti, P.G. Metastable Liquids (Princeton Univ, New Jersey, 1996)

10.Star, F. W, Angell, C. A.\& Stanley, H.E.Physica A 323, 51-66 (200B)

doi:101038/nature03707

\section{WATER BEHAVIOUR}

\section{Yue \& Angell reply}

\section{Reply to: Kohl, I. et al. Nature doi:10.1038/nature03707 (2005)}

The alternating support for and denial of a glass transition for amorphous water at $136 \mathrm{~K}$ has resumed after a hiatus of 20 years, during which it seemed secure. We revived the alternative interpretation ${ }^{1}$ by looking again at the calorimetric signal that previously provided the most direct evidence for the glass transition ${ }^{2,3}$ - and now Kohl et al. ${ }^{4}$ present new data to support the original interpretation. We show here that their results are also consistent with our conclusions.

The new data of Kohl et al. show that if the exceedinglyweak endothermic step (or peak), originally reported as being the glass-to-liquid transition $\left(T_{\mathrm{g}}\right)$ of water ${ }^{2}$, is a primary (glasslike) relaxation, then it is even weaker than previously supposed ${ }^{3}-$ only $3 \%$ above vibrational background and just a quarter the strength of the phenomenon that occurs in silica $\left(\mathrm{SiO}_{z}\right.$ the 'strongest' liquid known $\left.^{5}\right)$. If it is a glass transition, then it is the broadest on record for a single-component system, with $\Delta T_{\mathrm{g}} / T_{\mathrm{g}}=0.11$ (refs 3,5). As Kohl et al. observe, these characteristics would support the idea that water has undergone, during the hyperquench, a fragile-to-strong transition ${ }^{5}$, for 